\title{
(3) Magnetic Slow Relaxation in a Metal-Organic Framework Made of Chains of Ferromagnetically Coupled Single-Molecule Magnets
}

\author{
Gang Huang, ${ }^{[a]}$ Guglielmo Fernandez-Garcia, ${ }^{[b, c]}$ Insa Badiane, ${ }^{[a, d]}$ Magatte Camarra, ${ }^{[a, d]}$ \\ Stéphane Freslon, ${ }^{[\mathrm{a}]}$ Olivier Guillou, ${ }^{[\mathrm{a}]}$ Carole Daiguebonne, ${ }^{[\mathrm{a}]}$ Federico Totti, ${ }^{[\mathrm{c}]}$ Olivier Cador, ${ }^{[\mathrm{b}]}$ \\ Thierry Guizouarn, ${ }^{[b]}$ Boris Le Guennic, ${ }^{*[b]}$ and Kevin Bernot ${ }^{*[a]}$
}

\begin{abstract}
We report the study of a Dy-based metal-organic framework (MOF) with unprecedented magnetic properties. The compound is made of nine-coordinated Dy"l magnetic building blocks (MBBs) with poor intrinsic single-molecule magnet behavior. However, the MOF architecture constrains the MBBs in a one-dimensional structure that induces a ferromagnetic coupling between them. Overall, the material shows a magnetic slow relaxation in absence of external static field and a hysteretic behavior at $0.5 \mathrm{~K}$. Low-tempera-
\end{abstract}

ture magnetic studies, diamagnetic doping, and ab initio calculations highlight the crucial role played by the Dy-Dy ferromagnetic interaction. Overall, we report an original magnetic object at the frontier between single-chain magnets and single-molecule magnets that host intrachain couplings that cancel quantum tunneling between the MBBs. This compound is evidence that a bottom-up approach through MOF design can induce spontaneous organization of MBBs able to produce remarkable molecular magnetic materials.

\section{Introduction}

The organization of molecular magnetic building blocks (MBBs) into extended frameworks to form metal-organic frameworks (MOFs) is a dynamic field of research. ${ }^{[1,2]}$ MOFs have been proposed as a potential way to constrain coordination geometries of metallic ions to form arrays of single-molecule magnets $(\mathrm{SMMs})^{[3-5]}$ or single-chain magnets $(\mathrm{SCMs}) .^{[6,7]}$ This approach is particularly relevant when MBBs are made of lanthanide ions. ${ }^{[8,9]}$

In fact, high-performance lanthanide SMMs possess highly symmetric electrostatic environments that induce strong stabilization of the magnetic ground state. ${ }^{[10-13]}$ A striking illustra-

[a] Dr. G. Huang, Dr. I. Badiane, Dr. M. Camarra, S. Freslon, Prof. O. Guillou, Dr. C. Daiguebonne, Dr. K. Bernot

Univ. Rennes, INSA Rennes, CNRS

ISCR (Institut des Sciences Chimiques de Rennes) UMR 6226 35000 Rennes (France)

E-mail:kevin.bernot@insa-rennes.fr

[b] Dr. G. Fernandez-Garcia, Prof. O. Cador, T. Guizouarn, Dr. B. Le Guennic Univ. Rennes, CNRS

ISCR (Institut des Sciences Chimiques de Rennes) UMR 6226

35000 Rennes (France)

E-mail:boris.leguennic@univ-rennes1.fr

[c] Dr. G. Fernandez-Garcia, Prof. F. Totti

Laboratory of Molecular Magnetism (LaMM)

Università degli studi di Firenze, INSTM unit

Via della lastruccia 3, 50019 Sesto Fiorentino (Italy)

[d] Dr. I. Badiane, Dr. M. Camarra

LCPM-Groupe "Matériaux Inorganiques: Chimie Douce et Cristallographie" Université Assane Seck de Ziguinchor, BP 523 Ziguinchor (Sénégal)

$\square$ Supporting information and the ORCID identification number(s) for the au-

(iD thor(s) of this article can be found under https://doi.org/10.1002/ chem.201800095. tion of the latter concept is given by the Ln-phthalocyanine $(\mathrm{LnPc})$ systems, ${ }^{[14-17]}$ where the organic ligands impose a strict $D_{4 d}$ site symmetry to the lanthanide ion and dramatically improve its magnetic properties when compared with a distorted coordination environment. ${ }^{[18]}$ Compounds based on cyclooctatetraene (COT) are also remarkable examples of such an approach with $D_{8 d}$ symmetry able to induce strong SMM behavior in a wide range of lanthanide ions such as $\mathrm{Ce}^{\mathrm{III},}{ }^{[19]} \mathrm{Nd}^{\mathrm{III}}$, ${ }^{[20]}$ Dy"l ${ }^{\text {III] }}$ and Er ${ }^{\text {III }}{ }^{[22]}$ The library of such systems is continuously growing ${ }^{[9,13,23-26]}$ with the recently added pentagonal bipyramidal environment $\left(D_{5 h}\right)$ that provides excellent SMM behavior with Dy"II adducts. ${ }^{[27]}$ Last, an astonishing example of electrostatic engineering around a Dy"I center has been reported with observation of magnetic slow relaxation at record temperatures. ${ }^{\text {[28] }}$

However, as far as applications are targeted, a given Ln-SMM has to be converted into a material and then a device. To do so, different pathways can be followed. The first one is to isolate or organize the SMM on surfaces, a strategy that supposes solubility, ${ }^{[2,30]}$ evaporability, ${ }^{[31,32]}$ or substitution by grafting groups. ${ }^{[33,34]}$ However, this does not guarantee that the SMM properties are kept on surfaces ${ }^{[35]}$ as observed with the previously cited LnPc where excellent, ${ }^{[36,37]}$ erratic, ${ }^{[38]}$ or depth-dependent magnetic behavior on films is observed. ${ }^{[39]}$ Robustness of magnetic behavior of Ln-SMMs upon surface deposition is thus rarely observed. ${ }^{[40,41]}$

The second way is to organize the MBBs in the crystal packing $^{[42,43]}$ to optimize the overall magnetic behavior of the compound. Ideally, this may give rise to compounds where the MBBs are organized so that the molecular magnetic anisotropy axes point in the same direction to avoid cancellation of the magnetic moments. Little real control is observed on that 
point. Indeed, a real step-by-step procedure that relies on the isolation of a Ln-MBB and its organization into a MOF is rather scarce ${ }^{[42]}$ as reviewed recently. ${ }^{[5]}$ In most cases, magnetic MOFs are made of mono- ${ }^{[44-49]}$ or polynuclear ${ }^{[2,38,52-56]}$ MBBs that spontaneously organize in the crystal packing.

Magnetic MOFs have two main assets: their structural rigidity and their original topology. 1) The structural rigidity around the metallic center has been recently identified as a key factor for the observation of magnetic slow relaxation because it minimizes the phonon coupling responsible for the promotion of under-barrier relaxation pathways. ${ }^{[57]} 2$ ) The topology of the magnetic MOFs is able to induce magnetic behavior unobservable on the isolated MBBs such as dynamic magnetic behavior upon external stimuli ${ }^{[58]}$ or upon host-guest removal. ${ }^{[59]}$ Even non-porous MOFs can be appealing as the constraint on the chemical environment ${ }^{[1]}$ of the MBB can induce a strong magnetocaloric effect $(\mathrm{MCE})^{[60-63]}$ or three-dimensional (3D) magnetic ordering. ${ }^{[4,64-70]}$ This last feature implies strong magnetic interactions between the MBBs and we will focus on this particular point in this paper.

We report herein a MOF where spontaneous organization of the Dy-MBBs into chains is observed. This peculiar feature induces ferromagnetic intrachain interactions that promotes a fast-relaxing MBB into a material with magnetic slow relaxation and opening of a hysteresis at low temperature.

\section{Results and Discussion}

\section{Structural description}

The reaction of 1,2-phenylenediacetic acid $\left(\mathrm{H}_{2^{\circ}}-\mathrm{PDA}\right)$ with lanthanide chloride salts affords an isostructural series of three-dimensional MOF of general formula $\left[\left[\operatorname{Ln}(o-P D A)_{3}\left(\mathrm{H}_{2} \mathrm{O}\right)_{2}\right] \cdot 2 \mathrm{H}_{2} \mathrm{O}\right]_{n}$. The crystal structures have been reported for $\mathrm{Ln}=\mathrm{La}^{111},{ }^{[71]}$ $\mathrm{Nd}^{\text {III }}{ }^{[71]} \mathrm{Dy}^{\mathrm{III}},{ }^{[72]} \mathrm{Prr}^{[73]} \mathrm{Er}^{\mathrm{III}},{ }^{[73]} \mathrm{Tb}^{111},{ }^{[74]} \mathrm{Ho}^{\mathrm{III}}{ }^{[74]}$ with all derivatives obtained through hydrothermal syntheses. In this work, we have been able to obtain the same isostructural microcrystalline powders by using a soft chemistry reaction (see the Supporting Information) for $\mathrm{Ln}=\mathrm{Dy}$ "III (called Dy; Figure S1 in the Supporting Information) and for a doped derivative $\left[\left[D y_{0.08} \mathrm{Y}_{0.92}(O-P D A)_{3}\left(\mathrm{H}_{2} \mathrm{O}\right)_{2}\right] \cdot 2 \mathrm{H}_{2} \mathrm{O}\right]_{n}$ (called Y:Dy; Figure S2 in the Supporting Information). Hereafter, we provide a brief description of the crystal structure. ${ }^{[72]}$

Dy crystallizes in the monoclinic $C 2 / C$ space group. The asymmetric unit is made of one and a half 0 -PDA ${ }^{2-}$ ligand, one coordinated water molecule, half a Dy"l ion, and one uncoordinated water molecule. Each Dy"I ion is surrounded by nine oxygen atoms: one from a coordinated water molecule (O7) and eight from six different $0-$ PDA $^{2-}$ ligands. Four oxygen atoms $(01,02,04,06)$ bind only one Dy ${ }^{\prime \prime \prime}$ ion ( $\mu_{1}$ mode) and four oxygen atoms $(03,03 \mathrm{a}, \mathrm{O} 5, \mathrm{O} 5 \mathrm{a})$ bind two Dy"l ions $\left(\mu_{2}\right.$ mode; Figure 1 and Table S1 in the Supporting Information). From the magnetic point of view, this last coordination mode is expected to transmit a sizeable magnetic interaction between the Dy ${ }^{\text {III }}$ ions. ${ }^{[33,52,75]}$ The Dy ${ }^{\text {III }}$ ion presents a muffin-like coordination polyhedron $\left(C_{s}\right)^{[76]}$ (Figure 3, Table S2 in the Supporting Information).

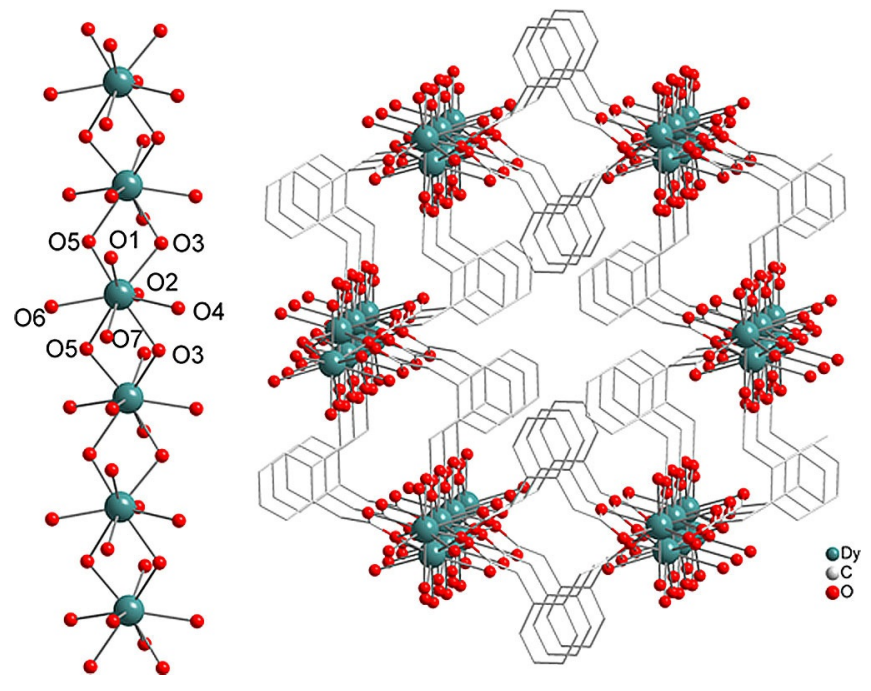

Figure 1. Left: Representation of the Dy"l chain that spreads along the $c$ axis, with labelling scheme. Right: Perspective crystal packing view close to the $c$ axis. Hydrogen atoms omitted for clarity.

Overall, Dy"I chains spread along the $c$ axis (Figure 1) and each o-PDA ${ }^{2-}$ ligand connects two parallel chains. The shortest Dy-Dy distance within a chain is $4.01(1) \AA$ and the interchain Dy-Dy distances are 7.82(2), 9.42(3), and 9.96(3) $\AA$ depending of the considered neighboring chain (Ch1, Ch2, and Ch3, see Figure 4). The network can be described as a $(6,3)$ topologic structure with a honeycomb-like core (Figure 1).

\section{Static magnetic properties}

The room-temperature $\chi_{M} T$ value measured for Dy is $13.64 \mathrm{~cm}^{3} \mathrm{Kmol}^{-1}$, which is close to that of the free ion $\left(14.17 \mathrm{~cm}^{3} \mathrm{~K} \mathrm{~mol}^{-1}\right)$. Upon cooling, a decrease of $\chi_{M} T$ is observed in line with the thermal depopulation of the $M_{\mathrm{J}}$ states (Figure 2). Below $20 \mathrm{~K}$, an abrupt increase is observed and $\chi_{\mathrm{M}} T$ reaches $30.6 \mathrm{~cm}^{3} \mathrm{Kmol}^{-1}$ at $2.0 \mathrm{~K}$ and a maximum of

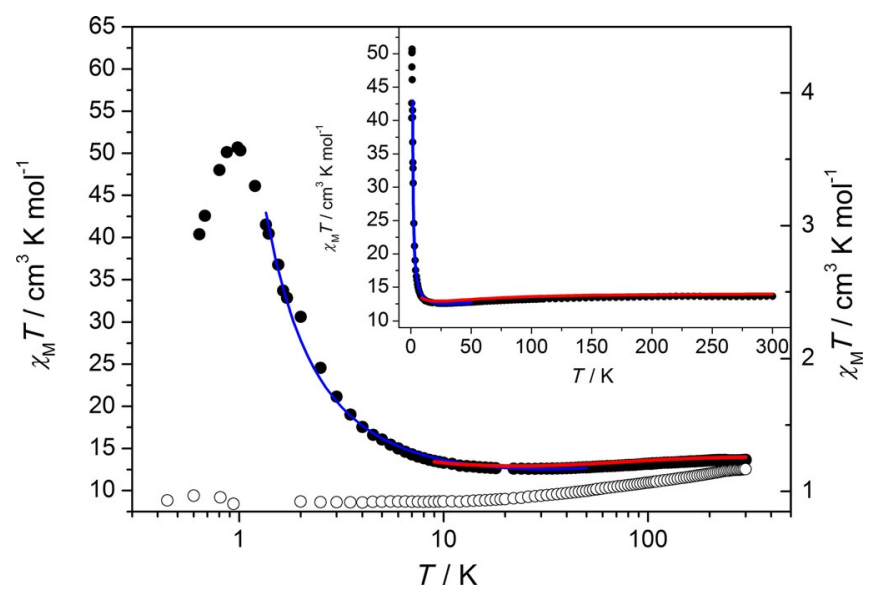

Figure 2. Temperature dependence of $\chi_{\mathrm{M}} T$ measured by static magnetic measurements for Dy (full symbols, left axis) and Y:Dy (empty symbols, right axis). Note the logarithmic temperature scale. Ab initio calculations are represented as a red line and best fit with Ising model as a blue line (see text). 
$50.69 \mathrm{~cm}^{3} \mathrm{~K} \mathrm{~mol}^{-1}$ at $1.0 \mathrm{~K}$. This sharp rise of $\chi_{\mathrm{M}} T$ is followed by a drop until $40.37 \mathrm{~cm}^{3} \mathrm{Kmol}^{-1}$ at $0.63 \mathrm{~K}$. It is worth noting that $\chi_{\mathrm{M}} T$ reconstruction from zero-field dynamic magnetic measurements affords a very similar temperature dependence (Figure S3 in the Supporting Information) and discards the occurrence of saturation effects. Consequently, both ferro- and antiferromagnetic couplings operate in Dy. The doped derivative, $\mathrm{Y}:$ Dy, depicts a monotonous decrease of $\chi_{\mathrm{M}} T$ that reaches a plateau below $11 \mathrm{~K}$, and validates its use as a magnetically uncoupled analog of Dy (Figure 2).

\section{$A b$ initio calculations and electrostatics}

In a first approximation, the strong ferromagnetic coupling observed in Dy is expected to be a consequence of the $\mu_{2}$ bridging mode of the oxygen atoms ( $\mathrm{O} 3$ and $\mathrm{O} 5$ ), which bind the Dy"l ion. ${ }^{[65,66,77]}$

To shed some light on this point, ab initio SA-CASSCF/SI-SO calculations have been performed (see the Supporting Information for details). A Dy ${ }^{\prime \prime \prime}$ ion has been considered together with its two closest neighbors within the chain as $Y^{\text {III }}$ ions
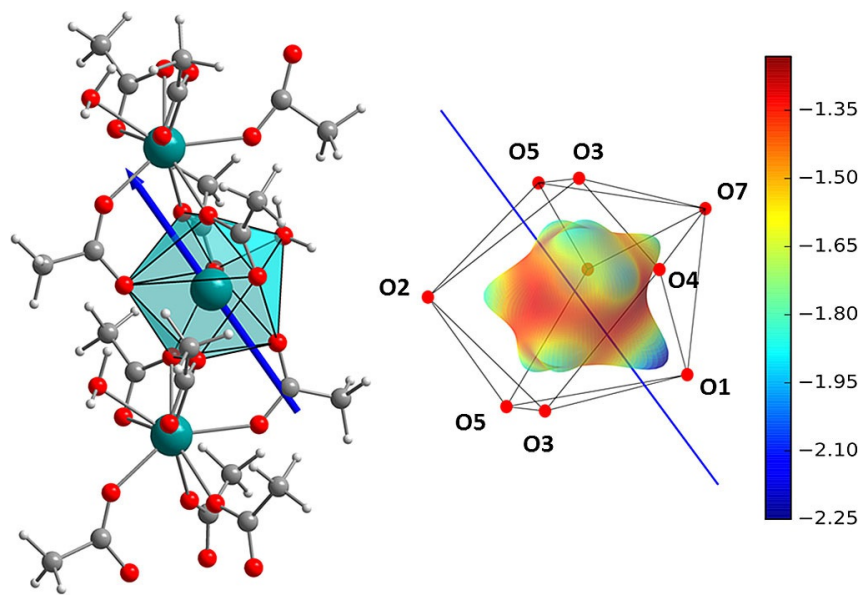

Figure 3. Left: Representation of the calculated easy-magnetic axis on a YDy'III-Y moiety. Right: Representation of the total electrostatics potential at $1.6 \AA$ around the Dy ${ }^{\text {III }}$ ion (the lowest and highest values are in blue and red, respectively), with the easy-axis direction as a blue line.

(Figure 3). All coordinated oxygen atoms have been considered explicitly. In fact, some of us have previously demonstrated that a too-simplified description of the neighboring environment of a given Dy'II in a Dy chain can lead to a wrong description of the electrostatic features of the compound. ${ }^{[78]}$ This system can be then considered as a good model of the doped compound Y:Dy.

The Dy ${ }^{\text {III }}$ ion is found to be extremely anisotropic $\left(g_{x}=0, g_{y}=\right.$ $\left.0.01, g_{z}=19.66\right)$ with an almost pure $15 / 2$ ground state that is very well separated from the first excited one by $203 \mathrm{~K}$ $\left(141 \mathrm{~cm}^{-1}\right.$; Table S3 and Figure S5 in the Supporting Information). This is a rare feature for a nine-coordinated Dy ${ }^{\text {III }}$ ion. ${ }^{[79]}$ The chain direction can be considered as the line connecting the $i$ th and $(i+2)$ th Dy ${ }^{\prime \prime \prime}$. The angle of the calculated easy-magnetic axis between two consecutive Dy $y^{\text {III }}$ is $16.89^{\circ}$ so that the

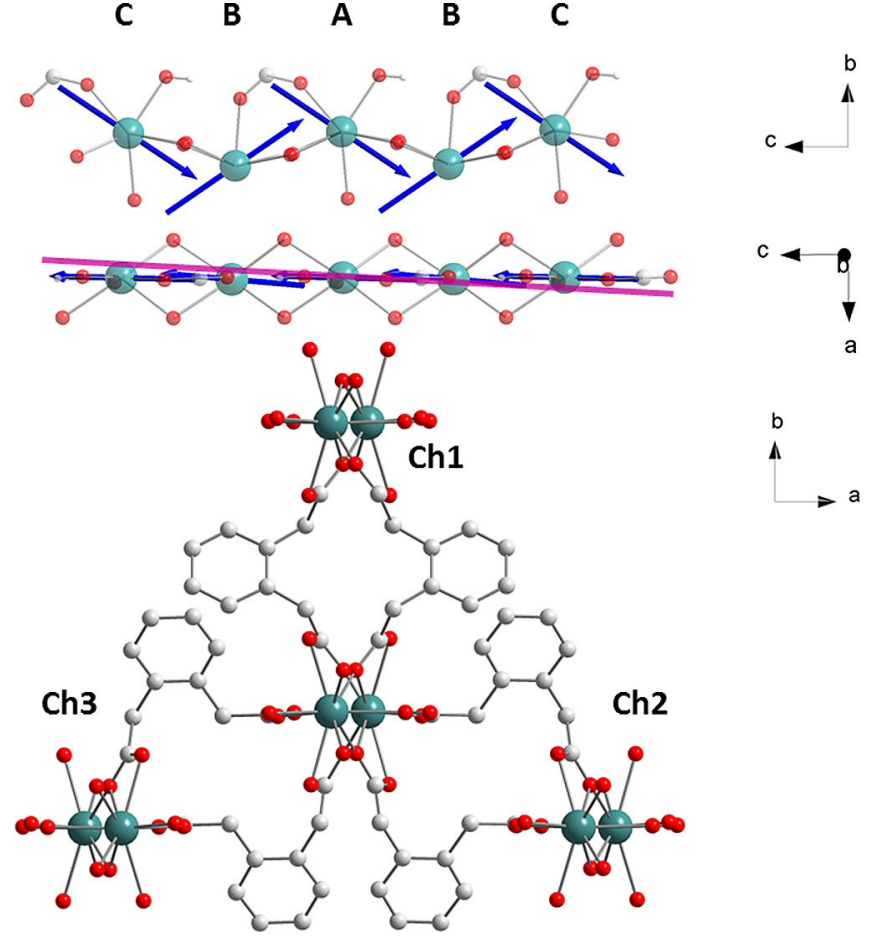

Figure 4. Top: Representation of the calculated easy-magnetic axes (blue). Middle: Representation of the easy-magnetic axes (blue) and of the resulting magnetic component along the chain. Bottom: Representation of the different chains considered for the calculations of dipolar coupling in Dy.

angle with the chain direction is $34.12^{\circ}$ (Figure 4). This slightly canted orientation is in line with a dipolar ferromagnetic DyDy interaction along the chain. Overall, the magnetic component of the chain lies in the $(a c)$ plane at $3.2^{\circ}$ from the chain direction.

It is well-known that the Ln-O binding is mainly electrostatic in nature and that the main anisotropy direction is governed by the minima in the electrostatic potential field. We employed then the home-developed CAMMEL code (CAlculated Molecular Multipolar ELectrostatics, see the Supporting Information) to analyze, at a radius of $1.6 \AA$ from the Dy center, the electrostatics extracted from the ab initio calculations.

It is clear from Figure 3 that the orientation of the $g$ tensor is heavily influenced by the contribution of a single oxygen atom (01); the latter is indeed at the shortest distance from the Dy III ion (Table S1 in the Supporting Information) and generates a more negative potential. However, looking at the single contributions in the multipolar expansion (Figure S4 in the Supporting Information), it is clear that this effect is not driven by the different charges in distribution of the oxygen atoms, but by the quadrupole moment (and to a lesser extent by the dipoles).

Magnetic interactions in Dy are attributable mainly to dipolar coupling because of the large distances between the metal sites. These interactions have been calculated by taking a Dy"' ion as reference and considering all its neighbors in a radius of $15 \AA$, by using the Lines model (see the Supporting Information). The interactions along the chain are all found to be ferromagnetic, with the one of the first neighbor's interactions 
being particularly strong $\left(J_{1}^{\text {dip }}=3.665 \mathrm{~cm}^{-1}\right.$ in the effective $S=$ $1 / 2$ framework, see also Figure 4, Table S4, and Figure S6 in the Supporting Information). The latter is also the only interaction that is expected to be not only dipolar in nature owing to a short distance of $4 \AA$. The interactions with the neighboring chains called $\mathrm{Ch} 1, \mathrm{Ch} 2$, and $\mathrm{Ch} 3$ are found to be both ferroand antiferromagnetic, but with a prevalence of antiferromagnetism. Indeed, the sum of all interactions from neighboring chain interactions leads to interchain coupling of $J_{\text {inter }}=$ $-0.048 \mathrm{~cm}^{-1}$.

\section{SMM versus SCM behavior}

At that stage, given the strong intramolecular ferromagnetic interaction observed in Dy, and the relatively high distances observed between the chains, one may expect single-chain magnet (SCM) behavior. ${ }^{[80-83]}$ Such behavior is seen when magnetic slow relaxation of a chain-based compound is confined inside the chain. The compound consequently behaves as a one-dimensional molecular magnet that adopts Ising-spin chain dynamics ${ }^{[7,84-88]}$ and can be described by the following spin Hamiltonian [Eq. (1)]:

$H_{\text {Ising }}=-\sum_{i j} J_{\text {Ising }(i j)} S_{i z} S_{j z}$

where $S_{i z}$ is the projection of the pseudospin eigenfunction on the axis of anisotropy of the ith site, collinear with the $j$ th site. From a static magnetic point of view, this implies the creation of magnetic domains within a chain where a given number of spin carriers can relax collectively. These coherent domains create a "correlation length" $\xi$, which is observed when the magnetic interaction along the chain is strong enough when compared with the temperature and possible weak interchain interactions. ${ }^{[86,89,90]}$ The growth of $\xi$ induces an exponential variation of $\chi_{M} T$ according to Equation (2): $:[7,65,66,77,91,92-94]$

$\chi_{\mathrm{M}} T \propto \exp \left(J_{\text {Ising }} / 2 k_{\mathrm{B}} T\right)$

On Dy, a $J_{\text {Ising }}$ value of $2.89 \mathrm{~cm}^{-1}$ is found in the $2-10 \mathrm{~K}$ temperature range. Consequently, we can discard SCM behavior in Dy because $J$ is considerably smaller than the energy barrier for spin reversal (see below) and the corresponding correlation length can be considered smaller than one repetitive unit.

Within the Lines model, we calculated the same interaction with $J_{\text {Ising }}=J_{\text {Lines }} \cos (\varphi)$ where $\varphi$ is the angle that projects the non-collinear Lines framework in the collinear Ising model. ${ }^{[95]}$ The fitted $J_{\text {Lines }} \approx 3.93 \mathrm{~cm}^{-1}$ with $\varphi \approx 50^{\circ}$ (see Figure $S 8$ in the Supporting Information) provides $J_{\text {Ising }}=2.53 \mathrm{~cm}^{-1}$. The difference between $J_{\text {Lines }}$ and $J_{1}^{\text {dip }}\left(3.66 \mathrm{~cm}^{-1}\right)$ comes from the exchange interaction that cannot be calculated owing to the complex network of dipolar couplings.

Overall, the observed magnetic behavior at low temperature $(0-1 \mathrm{~K})$ is explained by considering the system as Ising ferromagnetic chains, coupled by antiferromagnetic weak interactions.

\section{Dynamic magnetic properties}

Dynamic magnetic measurements have been performed on Dy and Y:Dy. In zero field $\left(H_{\mathrm{dc}}=0 \mathrm{Oe}\right)$, the two derivatives behave very differently. The relaxation time, $\tau$, measured for $D y$ is not affected by any temperature-independent phenomenon in all the investigated temperature range $(0.67-5 \mathrm{~K}$; Figures S9-S12 in the Supporting Information). This is an extremely rare feature as a levelling of $\tau$ is almost always observed on Dy'l'-based SMMs. ${ }^{[9]}$ Such levelling has been shown to be due to the occurrence of quantum tunneling, Raman, or direct relaxation processes that overcome the Orbach one at low temperature. ${ }^{[96]}$ For Dy, the strong magnetic coupling that operates between the Dy'II ions favors a pure thermally dependent relaxation process, which is expected to vary as $\tau=\tau_{0} \exp \left(\Delta / k_{\mathrm{B}} T\right)$ where $\tau_{0}$ is the characteristic relaxation time and $\Delta$ is the energy barrier for spin reversal. For Dy, these parameters are estimated to be $\tau_{0}=1.6 \times 10^{-5} \mathrm{~s}$ and $\Delta=9.1 \mathrm{~K}\left(6.3 \mathrm{~cm}^{-1}\right.$; see Table S6 in the Supporting Information). One can notice here that the physical meaning of $\Delta$ is far from a clear point as we are looking to an ensemble of coupled SMMs and not to an isolated magnetic molecule. Additionally, the distribution of the relaxation times is small above $1.8 \mathrm{~K}$ as demonstrated by the Cole-Cole plots $\left(\alpha_{1.8 \mathrm{~K}}=0.27\right.$, see Figure S14 and Table S7 in the Supporting Information) but increases as antiferromagnetic (AF) couplings became relevant $(\approx 1 \mathrm{~K})$. These Cole-Cole plots allow estimations for each temperature of the isothermal $\left(\chi_{T}\right)$ and adiabatic susceptibility $\left(\chi_{\mathrm{s}}\right)$ and consequently provide the relaxing fraction of the sample $\left(1-\left(\chi_{s} / \chi_{T}\right)\right)$. Almost all the sample relaxes slowly with a relaxing fraction of $99 \%$ and $93 \%$ at $0.8 \mathrm{~K}$ and $1.8 \mathrm{~K}$, respectively (Table $\mathrm{S} 7$ in the Supporting Information).

In-field measurements have been performed for $H_{\mathrm{dc}}=$ 1200 Oe, the field at which the slowest relaxation is observable at $2 \mathrm{~K}$ (Figure S15 in the Supporting Information). This induces a crossing between the Arrhenius plots extracted for $H_{\mathrm{dc}}=0$ Oe and $H_{\mathrm{dc}}=1200$ Oe (Figure 5) at $T \approx 1 \mathrm{~K}$. This is a rare feature as

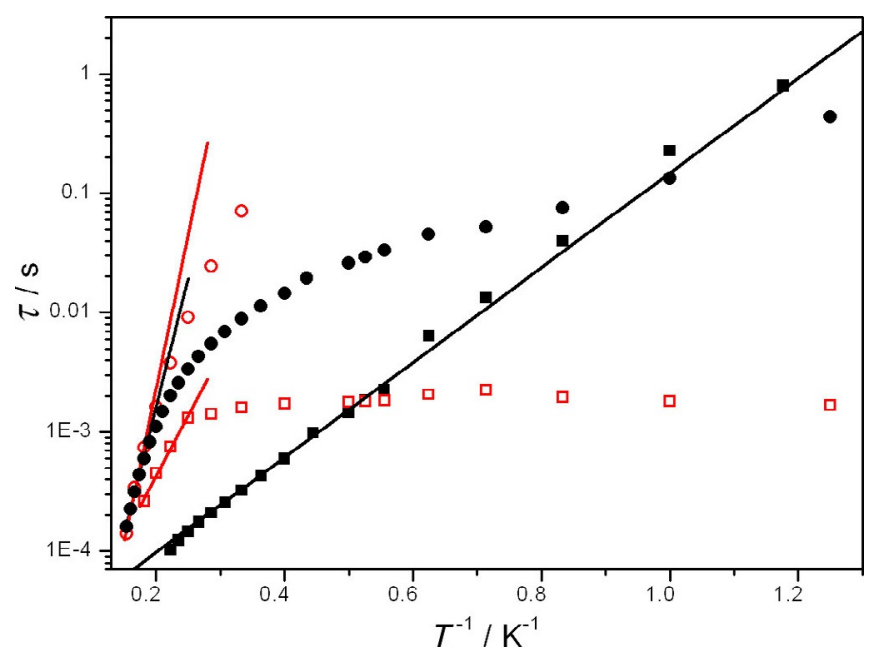

Figure 5. Plot of the relaxation times versus temperature for Dy (black symbols) and Y:Dy (red symbols) measured with $H_{\mathrm{dc}}=0$ Oe (squares) and $H_{\mathrm{dc}}=1200$ Oe (circles). Parameters for best fits are described in the text. 
magnetic relaxation below $1 \mathrm{~K}$ is slower in zero field than infield and induces an opening of an hysteresis that is not narrowed in zero field (butterfly-like hysteresis) as commonly observed on Dy ${ }^{\text {III }}$ adducts. ${ }^{[9,97,98]}$

In-field measurements show a thermally activated behavior far superior to the one in zero field with $\tau_{0}=8.0 \times 10^{-8} \mathrm{~s}$ and $\Delta=49.6 \mathrm{~K}\left(34.5 \mathrm{~cm}^{-1}\right.$; Tables S8-S9 in the Supporting Information). Despite a large relaxing fraction ( $84 \%$ and $96 \%$ at $0.8 \mathrm{~K}$ and $1.8 \mathrm{~K}$, respectively), a very high distribution of the relaxation times is observed $(\alpha=0.60$ and 0.50 at $0.8 \mathrm{~K}$ and $1.8 \mathrm{~K}$, respectively; Tables S8-S9, Figures S16-S20 in the Supporting Information). This may be a consequence of the competition between several relaxation processes. ${ }^{[99-101]}$ Indeed, a progressive levelling of $\tau$ is observed as the temperature is lowered (Figure 5). This is strikingly different from what is observed commonly for Dy III-SMMs where the application of a dc field induces a purer magnetic slow relaxation than in zero field. ${ }^{[96]}$

Magnetic dilution is a useful approach to investigate the magnetic properties of a given SMM without the influence of its magnetic neighbors. ${ }^{[102-114]}$ Once crystallized in an isomorphous diamagnetic matrix, the SMM behavior is generally optimized as intermolecular interactions that are likely to create additional and damaging pathways for the magnetic relaxation are suppressed. ${ }^{[105,114]}$ In the particular case of Dy, the magnetic dilution is a simple way to: 1) characterize the SMM properties of the isolated $M B B ; 2$ ) test the influence of the magnetic interactions (either along or between the chains) on the relaxing properties of the isolated Dy"I ion.

In zero field, the doped compound Y:Dy presents a thermal dependence of $\tau$ only above $4 \mathrm{~K}$ with Orbach parameters of $\tau_{0}=4.0 \times 10^{-6} \mathrm{~s}$ and $\Delta=23.4 \mathrm{~K}\left(16.2 \mathrm{~cm}^{-1}\right.$; Figures S21-S25, Tables $\mathrm{S} 10-\mathrm{S} 11$ in the Supporting Information). It is important to notice here that $\Delta$ is by far superior to the one observed on Dy, indicating that the isolated ion possesses a well-isolated ground state and possible good SMM performance. However, quantum tunneling relaxation processes are very efficient below $4 \mathrm{~K}$ and impose a totally thermally independent relaxation $(\tau \approx 100 \mathrm{~Hz})$. The relaxing fraction is very large $(90 \%$ and $95 \%$ at $0.8 \mathrm{~K}$ and $1.8 \mathrm{~K}$, respectively) with a severely damaged relaxation time distribution compared with Dy $\left(\alpha_{1.8 \mathrm{~K}}=0.58\right.$, whereas it was 0.27 for Dy). In-field measurements of Y:Dy, present a typical enhancement of the magnetic relaxation at high temperature, confirming the influence of quantum tunneling in zero field with $\tau_{0}=1.6 \times 10^{-8} \mathrm{~s}$ and $\Delta=59.5 \mathrm{~K}$ $\left(41.4 \mathrm{~cm}^{-1}\right.$; Figures S26-S31, Tables S12-S13 in the Supporting Information). These behaviors are in qualitative agreement with the ab initio magnetization barrier (Figure S5 in the Supporting Information), which suggests a relaxation pathway involving either an Orbach process from the first excited state or a quantum tunneling process from the second excited state. The fast thermally independent zero-field relaxation is not accounted by the ab initio calculations. This may suggest that additional fast relaxation processes are involved such as the contribution from hyperfine coupling with yttrium nuclear spin.

These findings clearly demonstrate that ferromagnetic couplings in Dy enhance its magnetic relaxation. Overall, Y:Dy has a slower magnetic relaxation than Dy at high temperature. However, below $1 \mathrm{~K}$, when the couplings are relevant, Dy is a better SMM than Y:Dy whatever $H_{\mathrm{dc}}$ is. This is further confirmed by hysteresis measurements.

\section{Hysteresis measurements}

Hysteresis curves have been recorded for Dy and Y:Dy at $0.47 \mathrm{~K}$ with a field sweep rate of $16 \mathrm{Oes}^{-1}$ (Figure 6). Dy shows

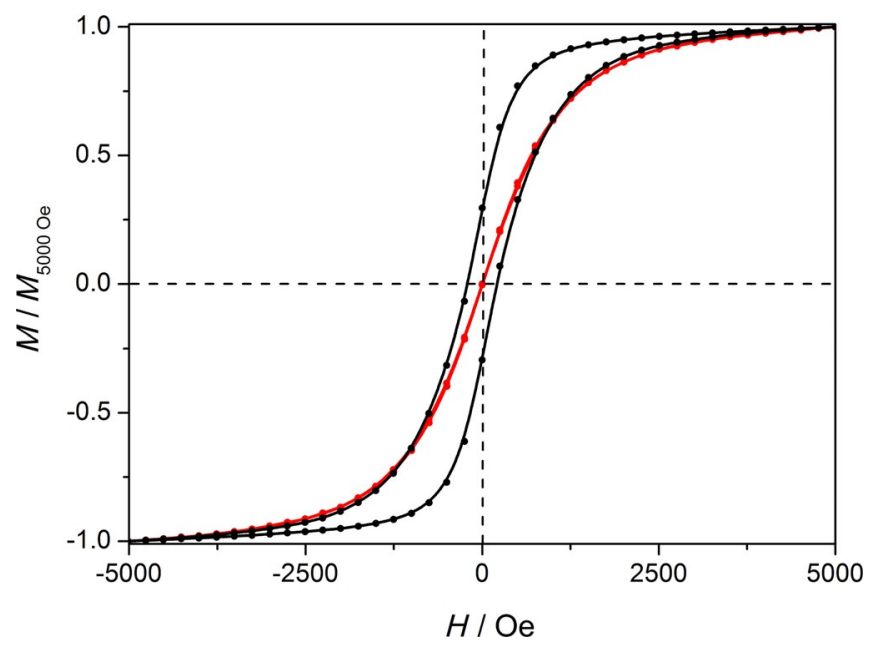

Figure 6. Hysteresis measurements of Dy and Y:Dy at $0.47 \mathrm{~K}$ with magnetic field sweep rate of $16 \mathrm{Oes}^{-1}$

an open hysteresis between \pm 5000 Oe with a coercitive field of $250 \mathrm{Oe}$, a remnant magnetization of $1.2 \mu_{\mathrm{B}}$ and saturation at $4 \mu_{\mathrm{B}}$. The hysteresis is no longer visible at higher fields but a stepped magnetization curve is observed $(6500 \mathrm{Oe})$, which further led to the expected $5 \mu_{B}$ saturation at 50000 Oe (Figure S32 in the Supporting Information). This is a signature of AF couplings between the chains.

The hysteresis observed at low fields is then suspected to be due to the ferromagnetic coupling between the MBBs along the chain. This is further confirmed by the closed hysteresis over the whole investigated field region for Y:Dy.

Dy can be described as a "pure $4 f^{\prime \prime}$ analog of $2 d-3 d{ }^{[115]} 3 d-$ $3 d^{\prime \prime},{ }^{[116-118]} 3 d-5 d,{ }^{[119]}$ or $4 f-5 d^{[120]}$ heterometallic chains. The strong anisotropy of the Dy-MBBs and the magnetic couplings in Dy preclude the occurrence of AF order as observed for some SCMs. ${ }^{[16,121,122]}$ Ferromagnetic couplings between the MBBs suppress the thermally independent relaxation pathways. Such behavior has been observed in the past for, among others, antiferromagnetically interacting $\mathrm{Mn}_{4}$ complexes, ${ }^{[123,124]}$ ferromagnetically coupled $\mathrm{Fe}_{4}$ supramolecular chains, ${ }^{[125]}$ cyanide-based SMMs, ${ }^{[126]}$ Dy radical tetramers, ${ }^{[127]}$ Dy ${ }^{11 !}$ dimers ${ }^{[128]}$ but, to the best of our knowledge, never for $4 \mathrm{f}$ chains.

\section{Conclusion}

Dy is a rare example of a compound made of nine-coordinated Dy ${ }^{\prime \prime \prime}$ ions that presents magnetic slow relaxation. Comparative studies of Dy and its doped derivative Y:Dy show that the Dy- 
MBB is strongly anisotropic, but relaxes quickly in zero field through temperature-independent relaxation processes. Ferromagnetic coupling between the MBBs cancels these processes and a ferromagnetic chain of MBBs is created at low temperature where MBBs display magnetic slow relaxation. The intrachain coupling is mainly dipolar but ab initio calculations show a small exchange contribution between nearest neighbors. Additionally, a close analysis of the interchain interactions highlights a global antiferromagnetic coupling between neighboring chains at very low temperature. Contrary to Y:Dy, a hysteretic behavior is observed for Dy, with opening in zero field. Overall, Dy is an original magnetic object at the frontier between single-chain magnets and single-molecule magnets. Indeed, it combines strong intrachain couplings with efficient cancelling of magnetic quantum tunneling. This is a key point as most of Dy'l'-based slow relaxing compounds show zerofield closed (butterfly-like) hysteresis, which is a severe limitation for their use in low-temperature magnetic memory devices. Ferromagnetic interactions between Dy-SMMs is then an efficient way to open their hysteresis in zero field. In this study, such interactions are tailored by the organization of the Dy ions in a metal-organic framework skeleton.

The MOF approach is also an efficient way to constrain catalytic clusters, ${ }^{[129]}$ chiral molecules, ${ }^{[130]}$ or $\mathrm{MBBs}^{[1,2]}$ into peculiar environments and consequently to induce original magnetic couplings. Usually, high-porosity MOFs are targeted because of their versatile magnetic dynamics upon guest exchange ${ }^{[59,131-133]}$ or capability to host SMMs. ${ }^{[134-136]}$ However, we show here that low-porosity MOFs made of $4 \mathrm{f} \mathrm{MBBs,}{ }^{[137]}$ such as Dy, should also be carefully considered. Last, the rigidity of these molecular edifices is an asset to minimize spin-phonon fast-relaxation mechanisms ${ }^{[57]}$ and thus may give rise to highperformance molecular magnets.

\section{Experimental Section}

\section{Synthetic procedure}

All reagents were purchased from $\mathrm{TCl}$ Chemicals and used without further purification. 1,2-Phenylenediacetic acid $(1.5 \mathrm{mmol})$ is deprotonated by an equivalent of $\mathrm{NaOH}$ in $\mathrm{H}_{2} \mathrm{O}(20 \mathrm{~mL})$. This solution was added directly into a stirred $\mathrm{LnCl}_{3} \cdot 6 \mathrm{H}_{2} \mathrm{O}(1.5 \mathrm{mmol})$ aqueous solution to produce white precipitates. The precipitates were filtered and washed with distilled water and finally dried in air. The yttrium-doped derivative is obtained with a similar procedure by using the appropriate lanthanide chloride salts in a 9:1 (Y/Dy) ratio.

\section{X-ray powder diffraction}

Experimental diffractograms were collected with a Panalytical $X^{\prime}$ pert Pro diffractometer equipped with an X'Celerator detector and a copper source $\mathrm{Cu}_{\mathrm{k} \alpha}=1.542 \AA$. Recording conditions in $\theta-\theta$ mode were $45 \mathrm{kV}, 40 \mathrm{~mA}$, step size $0.0084^{\circ}$, scan per step $50 \mathrm{~s}$. Calculated diffractograms were produced by using mercury software from CCDC.

\section{Energy-dispersive X-ray spectroscopy (EDS) analysis}

Measurements were carried out with a Hitachi TM-1000, Tabletop microscope version 02.11 (Hitachi High-Technologies, Corporation
Tokyo Japan) with an EDS analysis system (SwiftED-TM, Oxford Instruments Link INCA). The instrument is equipped with a silicon drift detector with an energy resolution of $165 \mathrm{eV}$. Samples were observed by means of an electron beam accelerated at $15 \mathrm{kV}$, under high vacuum. Samples were put on carbon discs, stuck on an aluminium stub fixed at $7 \mathrm{~mm}$ from the beam, with an angle of measurement of $22^{\circ}$. Reproducibility of the elemental analyses was carefully checked by reproducing several times the measurements on six different sample locations (see the Supporting Information).

\section{Magnetic measurements}

Magnetic measurements were performed with a Quantum Design MPMS magnetometer by using polycrystalline samples compacted into pellets to avoid crystallite orientation under the magnetic field. Measurements were corrected for diamagnetic contributions calculated with Pascal constants. Hysteresis curves were measured with a ${ }^{3} \mathrm{He}$ insert in the same magnetometer with a field sweep rate of $16 \mathrm{Oes}^{-1}$.

\section{Electrostatics analysis with CAMMEL code}

The home-made CAlculated Molecular Multipolar Electrostatics code (CAMMEL) allows the calculation of the electrostatic potential generated by the ligands at a given radius from the metallic center, following Equation (3):

$V\left(r_{i}\right)=\sum_{i}^{N} \frac{q_{i}}{\left|r_{i}-r\right|}+\frac{p_{i} r_{i}}{\left|r_{i}-r\right|^{3}}+\frac{r_{i}\left(Q_{i} r_{i}\right)}{\left|r_{i}-r\right|^{5}}$

where $q_{i}, p_{i}$, and $Q_{i}$ are the charge, dipole moment, and quadrupole moment, respectively, of the ith atom of the ligand, whereas $r_{i}$ is the position vector of the ith atom. All the charges and moments are extracted from ab initio calculations (see above) followed by a LOPROP ${ }^{[13]}$ analysis of the electronic density. It is important to stress that this method is an analysis of the results of calculations done with high level of theory and therefore it does not have any prediction power by itself. The potential is calculated on a sphere with a radius given by the user and its intensity is represented with a color code (blue = low potential, red=high potential). For the sake of graphics, it can be represented as irregular surfaces in which the height of the surface is also proportional to the value of the potential. This representation is considered more intuitive. The code can also represent individually each component (charge, dipole, and quadrupole potential) to give insights into which part is the dominant one.

\section{Calculation of dipolar couplings}

For the calculation of the isotropic dipolar coupling, we considered the anisotropy of each center as locally Ising $\left(g_{x x}=g_{y y}=0\right)$ and therefore we employed the following equation [Eq. (4)]:

$J_{i j}^{\text {dipolar }}=\frac{\mu_{\mathrm{B}}^{2}}{3 R^{3}}\left[g_{z z i} g_{z z j}\left(\cos \gamma_{i j}-3 \cos \theta_{i} \cos \theta_{i}\right)\right]$

where $\mu_{\mathrm{B}}{ }^{2}$ is the Bohr magneton, $R$ is the distance between the centers (the module of the distance vector), $g_{z z i}$ is the component along the $z$ direction of the g-tensor for the ith center, $\theta_{i}$ is the angle between the distance vector and the eigenvector of the $\mathrm{g}$ tensor corresponding to $g_{z z i}$ (the anisotropy axis), and $\gamma_{i j}$ is the angle between the anisotropy axis of the two centers. It was not possible to include in our calculation any kind of exchange interaction (not even with a Lines model) between the nearest neighbors: 
the not-negligible dipolar interactions have an extension until $\approx 12 \AA$ and so, to model properly both dipolar and exchange interactions, it would have been necessary to include a total of 12 metallic ions. Clearly such calculation is too demanding in terms of hardware resources. Moreover, the strength of the close-range interactions (see $J_{1}$ and $J_{2}$ in Table $S 4$ in the Supporting Information) poses a not trivial issue in the fitting of a $J_{\text {exchange }}$ parameter, as we expect it to be orders of magnitude lower than the first-neighbor $J_{\text {dip }}$. Therefore, the variance of the exchange parameter, in the Lines model, would be too high to allow a quantitative analysis.

Additional information about ab-initio calculations are provided in the Supporting Information.

\section{Acknowledgments}

We acknowledge financial support from INSA Rennes, Rennes Metropole, China Scholarship Council, CNRS, Université de Rennes 1, and Region Bretagne. K.B. acknowledges the Institut Universitaire de France, G.F.G. gratefully acknowledges the European Commission through ERC-AdG 267746 MolNanoMas (project no. 267746) and the ANR (ANR-13-BS07-0022-01) for financial support. B.L.G. and G.F.G. thank the French GENCI/ IDRIS-CINES centre for high-performance computing resources.

\section{Conflict of interest}

The authors declare no conflict of interest.

Keywords: ferromagnetic coupling - lanthanides - metalorganic frameworks · single-chain magnets $\cdot$ single-molecule magnets

[1] K. Liu, X. Zhang, X. Meng, W. Shi, P. Cheng, A. K. Powell, Chem. Soc. Rev. 2016, 45, 2423-2439.

[2] K. Liu, H. Li, X. Zhang, W. Shi, P. Cheng, Inorg. Chem. 2015, 54, 10224 10231.

[3] S. Gao, Molecular Nanomagnets and Related Phenomena, Vol. 164, Springer, Berlin, 2015.

[4] C. Benelli, D. Gatteschi, Introduction to Molecular Magnetism: From Transition Metals to Lanthanides, Wiley-VCH, Weinheim, 2015.

[5] I. R. Jeon, R. Clérac, Dalton Trans. 2012, 41, 9569-9586.

[6] H. Miyasaka, M. Julve, M. Yamashita, R. Clerac, Inorg. Chem. 2009, 48, 3420-3437.

[7] C. Coulon, H. Miyasaka, R. Clérac, in Single-Molecule Magnets and Related Phenomena, Vol. 122 (Ed.: R. Winpenny), Springer, Berlin, Heidelberg, 2006, pp. 163-206.

[8] O. Guillou, C. Daiguebonne, in Handbook on the Physics and Chemistry of Rare Earths, Vol. 34 (Eds.: K. A. Gschneider, J.-C. G. Bünzli, V. K. Pecharsky), Elsevier, Amsterdam, 2005, pp. 359-404.

[9] D. N. Woodruff, R. E. P. Winpenny, R. A. Layfield, Chem. Rev. 2013, 113, 5110-5148.

[10] L. Ungur, L. F. Chibotaru, Chem. Eur. J. 2017, 23, 3708-3718.

[11] F.-S. Guo, B. M. Day, Y.-C. Chen, M.-L. Tong, A. Mansikamäkki, R. A. Layfield, Angew. Chem. Int. Ed. 2017, 56, 11445-11449; Angew. Chem. 2017, 129, $11603-11607$.

[12] T. Pugh, N. F. Chilton, R. A. Layfield, Angew. Chem. Int. Ed. 2016, 55, 11082-11085; Angew. Chem. 2016, 128, 11248-11251.

[13] K. L. M. Harriman, J. L. Brosmer, L. Ungur, P. L. Diaconescu, M. Murugesu, J. Am. Chem. Soc. 2017, 139, 1420-1423.

[14] N. Ishikawa, M. Sugita, T. Ishikawa, S.-y. Koshihara, Y. Kaizu, J. Am. Chem. Soc. 2003, 125, 8694-8695.

[15] N. Ishikawa, Polyhedron 2007, 26, 2147-2153.
[16] C. R. Ganivet, B. Ballesteros, G. de la Torre, J. M. Clemente-Juan, E. Coronado, T. Torres, Chem. Eur. J. 2013, 19, 1457-1465.

[17] H. Wang, B.-W. Wang, Y. Bian, S. Gao, J. Jiang, Coord. Chem. Rev. 2016 306, 195-216.

[18] S.-D. Jiang, B.-W. Wang, G. Su, Z.-M. Wang, S. Gao, Angew. Chem. Int Ed. 2010, 49, 7448-7451; Angew. Chem. 2010, 122, 7610-7613.

[19] J. J. Le Roy, I. Korobkov, J. E. Kim, E. J. Schelter, M. Murugesu, Dalton Trans. 2014, 43, 2737-2740.

[20] J. J. Le Roy, S. I. Gorelsky, I. Korobkov, M. Murugesu, Organometallics 2015, 34, 1415-1418.

[21] J. J. Le Roy, M. Jeletic, S. I. Gorelsky, I. Korobkov, L. Ungur, L. F. Chibotaru, M. Murugesu, J. Am. Chem. Soc. 2013, 135, 3502-3510.

[22] L. Ungur, J. J. Le Roy, I. Korobkov, M. Murugesu, L. F. Chibotaru, Angew. Chem. Int. Ed. 2014, 53, 4413-4417; Angew. Chem. 2014, 126, $4502-$ 4506.

[23] Y.-S. Meng, S.-D. Jiang, B.-W. Wang, S. Gao, Acc. Chem. Res. 2016, 49, $2381-2389$.

[24] E. Lucaccini, M. Briganti, M. Perfetti, L. Vendier, J.-P. Costes, F. Totti, R. Sessoli, L. Sorace, Chem. Eur. J. 2016, 22, 5552-5562.

[25] F. Pointillart, O. Cador, B. Le Guennic, L. Ouahab, Coord. Chem. Rev. 2017, 346, 150-175.

[26] R. A. Layfield, Organometallics 2014, 33, 1084-1099.

[27] Y.-S. Ding, N. F. Chilton, R. E. P. Winpenny, Y.-Z. Zheng, Angew. Chem. Int. Ed. 2016, 55, 16071-16074; Angew. Chem. 2016, 128, $16305-$ 16308.

[28] C. A. P. Goodwin, F. Ortu, D. Reta, N. F. Chilton, D. P. Mills, Nature 2017, $548,439-442$

[29] T. T. da Cunha, J. Jung, M. E. Boulon, G. Campo, F. Pointillart, C. L. M. Pereira, B. Le Guennic, O. Cador, K. Bernot, F. Pineider, S. Golhen, L. Ouahab, J. Am. Chem. Soc. 2013, 135, 16332-16335.

[30] H. Z. Kou, S. Gao, C. H. Li, D. Z. Liao, B. C. Zhou, R. J. Wang, Y. D. Li, Inorg. Chem. 2002, 41, 4756-4762.

[31] C. Gao, Q. Yang, B.-W. Wang, Z.-M. Wang, S. Gao, CrystEngComm 2016, $18,4165-4171$.

[32] X. Yi, K. Bernot, F. Pointillart, G. Poneti, G. Calvez, C. Daiguebonne, O. Guillou, R. Sessoli, Chem. Eur. J. 2012, 18, 11379-11387.

[33] A. Cornia, M. Mannini, in Molecular Nanomagnets and Related Phenomena, Springer, Berlin, Heidelberg, 2014, pp. 1-38.

[34] R. J. Holmberg, M. Murugesu, J. Mater. Chem. C 2015, 3, 11986-11998.

[35] M. Mannini, F. Pineider, P. Sainctavit, C. Danieli, E. Otero, C. Sciancalepore, A. M. Talarico, M. A. Arrio, A. Cornia, D. Gatteschi, R. Sessoli, Nat. Mater. 2009, 8, 194-197.

[36] M. Mannini, F. Bertani, C. Tudisco, L. Malavolti, L. Poggini, K. Misztal, D. Menozzi, A. Motta, E. Otero, P. Ohresser, P. Sainctavit, G. G. Condorelli, E. Dalcanale, R. Sessoli, Nat. Commun. 2014, 5, 4582.

[37] L. Margheriti, D. Chiappe, M. Mannini, P. E. Car, P. Sainctavit, M. A. Arrio, F. B. de Mongeot, J. C. Cezar, F. M. Piras, A. Magnani, E. Otero, A Caneschi, R. Sessoli, Adv. Mater. 2010, 22, 5488-5493.

[38] L. Malavolti, M. Mannini, P.-E. Car, G. Campo, F. Pineider, R. Sessoli, J. Mater. Chem. C 2013, 1, 2935-2942.

[39] A. Hofmann, Z. Salman, M. Mannini, A. Amato, L. Malavolti, E. Morenzoni, T. Prokscha, R. Sessoli, A. Suter, ACS Nano 2012, 6, 8390-8396.

[40] E. Kiefl, M. Mannini, K. Bernot, X. Yi, A. Amato, T. Leviant, A. Magnani, T. Prokscha, A. Suter, R. Sessoli, Z. Salman, ACS Nano 2016, 10, $5663-$ 5669.

[41] I. Cimatti, X. Yi, R. Sessoli, M. Puget, B. Le Guennic, J. Jung, T. Guizouarn, A. Magnani, K. Bernot, M. Mannini, Appl. Surf. Sci. 2018, 432, $7-14$.

[42] X. Yi, G. Calvez, C. Daiguebonne, O. Guillou, K. Bernot, Inorg. Chem. 2015, 54, 5213-5219.

[43] R. Sessoli, K. Bernot, in Lanthanides and Actinides in Molecular Magnetism, Wiley-VCH, Weinheim, 2015, pp. 89-124.

[44] C.-M. Liu, D. Zhang, X. Hao, D.-B. Zhu, ACS Omega 2016, 1, 286-292.

[45] C.-M. Liu, D.-Q. Zhang, Y.-S. Zhao, X. Hao, D.-B. Zhu, Inorg. Chem. Front. 2016, 3, 1076-1081.

[46] C.-M. Liu, D.-Q. Zhang, D.-B. Zhu, Chem. Commun. 2016, 52, $4804-$ 4807.

[47] C.-M. Liu, J. Xiong, D.-Q. Zhang, B.-W. Wang, D.-B. Zhu, RSC Adv. 2015, 5, 104854-104861.

[48] M. Chen, E. C. Sañudo, E. Jiménez, S.-M. Fang, C.-S. Liu, M. Du, Inorg. Chem. 2014, 53, 6708-6714. 
[49] M. N. Akhtar, Y.-C. Chen, M. A. AlDamen, M.-L. Tong, Dalton Trans. 2017, 46, 116-124.

[50] J. Campo, L. R. Falvello, E. Forcen-Vazquez, C. Saenz de Pipaon, F. Palacio, M. Tomas, Dalton Trans. 2016, 45, 16764-16768.

[51] P. H. Lin, T. J. Burchell, R. Clerac, M. Murugesu, Angew. Chem. Int. Ed. 2008, 47, 8848-8851; Angew. Chem. 2008, 120, 8980-8983.

[52] Y.-X. Ren, X.-J. Zheng, L.-C. Li, D.-Q. Yuan, M. An, L.-P. Jin, Inorg. Chem. 2014, 53, 12234-12236.

[53] C.-M. Liu, D.-Q. Zhang, X. Hao, D.-B. Zhu, RSC Adv. 2015, 5, 92980 92987.

[54] X. Ma, N. Xu, C. Gao, L. Li, B. Wang, W. Shi, P. Cheng, Dalton Trans. 2015, 44, 5276-5279.

[55] Z. Chen, B. Zhao, P. Cheng, X. Q. Zhao, W. Shi, Y. Song, Inorg. Chem 2009, 48, 3493-3495.

[56] X. H. Yi, K. Bernot, G. Calvez, C. Daiguebonne, O. Guillou, Eur. J. Inorg Chem. 2013, 5879-5885.

[57] A. Lunghi, F. Totti, R. Sessoli, S. Sanvito, Nat. Commun. 2017, 8, 14620

[58] E. Coronado, G. Minguez Espallargas, Chem. Soc. Rev. 2013, 42, 1525 1539.

[59] X. Zhang, V. Vieru, X. Feng, J.-L. Liu, Z. Zhang, B. Na, W. Shi, B.-W Wang, A. K. Powell, L. F. Chibotaru, S. Gao, P. Cheng, J. R. Long, Angew. Chem. Int. Ed. 2015, 54, 9861 -9865; Angew. Chem. 2015, 127, $9999-$ 10003.

[60] J. W. Sharples, D. Collison, in Lanthanides and Actinides in Molecular Magnetism, Wiley-VCH, Weinheim, 2015, pp. 293-314.

[61] G. Lorusso, J. W. Sharples, E. Palacios, O. Roubeau, E. K. Brechin, R. Ses soli, A. Rossin, F. Tuna, E. J. L. McInnes, D. Collison, M. Evangelisti, Adv. Mater. 2013, 25, 4653-4656.

[62] R. Sibille, T. Mazet, B. Malaman, M. François, Chem. Eur. J. 2012, 18, $12970-12973$.

[63] G. Lorusso, M. A. Palacios, G. S. Nichol, E. K. Brechin, O. Roubeau, M. Evangelisti, Chem. Commun. 2012, 48, $7592-7594$.

[64] H. Tian, X. Wang, X. Mei, R. Liu, M. Zhu, C. Zhang, Y. Ma, L. Li, D. Liao, Eur. J. Inorg. Chem. 2013, 1320-1325.

[65] E. Bartolomé, J. Bartolomé, S. Melnic, D. Prodius, S. Shova, A. Arauzo, J. Luzon, L. Badia-Romano, F. Luis, C. Turta, Dalton Trans. 2014, 43, 10999-11013

[66] E. Bartolomé, J. Bartolomé, S. Melnic, D. Prodius, S. Shova, A. Arauzo, J. Luzon, F. Luis, C. Turta, Dalton Trans. 2013, 42, 10153-10171.

[67] R. N. Liu, C. M. Zhang, X. L. Mei, P. Hu, H. X. Tian, L. C. Li, D. Z. Liao, J. P. Sutter, J. New Chem. 2012, 36, 2088-2093.

[68] Y. Guo, G. F. Xu, C. Wang, T. T. Cao, J. K. Tang, Z. Q. Liu, Y. Ma, S. P. Yan, P. Cheng, D. Z. Liao, Dalton Trans. 2012, 41, 1624-1629.

[69] M. Evangelisti, F. Luis, F. L. Mettes, N. Aliaga, G. Aromí, J. J. Alonso, G. Christou, L. J. de Jongh, Phys. Rev. Lett. 2004, 93, 117202.

[70] C. Benelli, A. Caneschi, D. Gatteschi, R. Sessoli, Adv. Mater. 1992, 4, 504-505.

[71] L.-J. Chen, X. Chen, Q.-B. Hou, M.-X. Yang, S. Lin, J. Chin. Inorg. Chem. 2014, 30, 786-792

[72] C.-Y. Wang, X.-S. Wu, X. Li, J. Chin. Inorg. Chem. 2008, 24, 781-784.

[73] M.-L. Zhang, X.-L. Chen, J.-J. Wang, J. Chin. Struct. Chem. 2014, 33, 935-941.

[74] X. Li, C. Wang, X. Zheng, Y. Zou, J. Coord. Chem. 2008, 61, 1127-1136.

[75] S. Biswas, S. Das, G. Rogez, V. Chandrasekhar, Eur. J. Inorg. Chem. 2016, $3322-3329$.

[76] S. Alvarez, P. Alemany, D. Casanova, J. Cirera, M. Llunell, D. Avnir, Coord. Chem. Rev. 2005, 249, $1693-1708$.

[77] E. Bartolomé, J. Bartolomé, A. Arauzo, J. Luzon, L. Badia, R. Cases, F. Luis, S. Melnic, D. Prodius, S. Shova, C. Turta, J. Mater. Chem. C 2016, 4, $5038-5050$.

[78] J. Jung, F. Le Natur, O. Cador, F. Pointillart, G. Calvez, C. Daiguebonne, O. Guillou, T. Guizouarn, B. Le Guennic, K. Bernot, Chem. Commun. 2014, 50, 13346-13348.

[79] S. Gómez-Coca, D. Aravena, R. Morales, E. Ruiz, Coord. Chem. Rev. 2015, 289-290, 379-392.

[80] Y.-D. Luo, G.-M. Sun, D.-M. Li, F. Luo, Inorg. Chem. Commun. 2011, 14, $778-780$.

[81] L. Su, W.-C. Song, J.-P. Zhao, F.-C. Liu, Chem. Commun. 2016, 52, 8722 8725.

[82] P. C. M. Arosio, M. Mariani, F. Orsini, L. Bogani, A. Caneschi, J. Lago, A. Lascialfari, J. Appl. Phys. 2015, 117, 17B310.
[83] Y.-C. Hui, Y.-S. Meng, Z. Li, Q. Chen, H.-L. Sun, Y.-Q. Zhang, S. Gao, CrystEngComm 2015, 17, 5620-5624.

[84] M. G. F. Vaz, R. A. A. Cassaro, H. Akpinar, J. A. Schlueter, P. M. Lahti, M. A. Novak, Chem. Eur. J. 2014, 20, 5460-5467.

[85] K. Bernot, L. Bogani, R. Sessoli, D. Gatteschi, Inorg. Chim. Acta 2007 360, 3807-3812.

[86] L. Bogani, C. Sangregorio, R. Sessoli, D. Gatteschi, Angew. Chem. Int. Ed. 2005, 44, 5817-5821; Angew. Chem. 2005, 117, 5967-5971.

[87] C. Coulon, H. Miyasaka, R. Clerac, in Single-Molecule Magnets and Related Phenomena, Vol. 122 (Ed.: R. Winpenny), Springer, Berlin, 2006, pp. $163-206$.

[88] A. Saitoh, H. Miyasaka, M. Yamashita, R. Clerac, J. Mater. Chem. 2007 17, 2002-2012.

[89] O. V. Billoni, V. Pianet, D. Pescia, A. Vindigni, Phys. Rev. B 2011, 84, 064415.

[90] Y.-Z. Zheng, Y. Lan, W. Wernsdorfer, C. E. Anson, A. K. Powell, Chem Eur. J. 2009, 15, 12566-12570.

[91] K. Bernot, L. Bogani, A. Caneschi, D. Gatteschi, R. Sessoli, J. Am. Chem. Soc. 2006, 128, 7947-7956.

[92] L. Bogani, A. Vindigni, R. Sessoli, D. Gatteschi, J. Mater. Chem. 2008, 18, $4750-4758$.

[93] P. Hu, X. Wang, Y. Ma, Q. Wang, L. Li, D. Liao, Dalton Trans. 2014, 43 $2234-2243$.

[94] D. Gatteschi, R. Sessoli, A. Caneschi, L. Bogani, A. Vindigni, in 225th National Meeting of the American Chemical Society, New Orleans, Louisiana, 2003, pp. U147-U147.

[95] L. F. Chibotaru, L. Ungur, A. Soncini, Angew. Chem. Int. Ed. 2008, 47, 4126-4129; Angew. Chem. 2008, 120, 4194-4197.

[96] S. T. Liddle, J. van Slageren, Chem. Soc. Rev. 2015, 44, 6655-6669.

[97] P. Selvanathan, G. Huang, T. Guizouarn, T. Roisnel, G. Fernandez-Garcia, F. Totti, B. Le Guennic, G. Calvez, K. Bernot, L. Norel, S. Rigaut, Chem. Eur. J. 2016, 22, 15222-15226.

[98] F. Pointillart, K. Bernot, S. Golhen, B. Le Guennic, T. Guizouarn, L. Ouahab, O. Cador, Angew. Chem. Int. Ed. 2015, 54, 1504-1507; Angew. Chem. 2015, 127, 1524-1527.

[99] D. Zhang, Y.-M. Tian, W.-B. Sun, H.-F. Li, P. Chen, Y.-Q. Zhang, P.-F. Yan, Dalton Trans. 2016, 45, 2674-2680.

[100] Y.-S. Meng, Y.-S. Qiao, Y.-Q. Zhang, S.-D. Jiang, Meng, B.-W. Wang, Z.-M. Wang, S. Gao, Chem. Eur. J. 2016, 22, 4704-4708.

[101] A. J. Calahorro, I. Oyarzabal, B. Fernandez, J. M. Seco, T. Tian, D. FairenJimenez, E. Colacio, A. Rodriguez-Dieguez, Dalton Trans. 2016, 45, $591-598$.

[102] A. Amjad, A. M. Madalan, M. Andruh, A. Caneschi, L. Sorace, Chem. Eur. J. 2016, 22, 12849-12858.

[103] A. Biltmo, P. Henelius, Phys. Rev. B 2008, 78, 054437.

[104] C. M. S. Gannarelli, D. M. Silevitch, T. F. Rosenbaum, G. Aeppli, A. Fisher, Phys. Rev. B 2012, 86, 014420.

[105] F. Habib, P.-H. Lin, J. Long, I. Korobkov, W. Wernsdorfer, M. Murugesu, J. Am. Chem. Soc. 2011, 133, 8830-8833.

[106] J. Liu, Y.-C. Chen, J.-J. Lai, Z.-H. Wu, L.-F. Wang, Q.-W. Li, G.-Z. Huang, J.H. Jia, M.-L. Tong, Inorg. Chem. 2016, 55, 3145-3150.

[107] M. N. Popova, E. P. Chukalina, B. Z. Malkin, S. K. Saikin, Phys. Rev. B 2000, 61, 7421-7427.

[108] J. A. Quilliam, S. Meng, J. B. Kycia, Phys. Rev. B 2012, 85, 184415.

[109] J. Rodriguez, A. A. Aczel, J.P. Carlo, S. R. Dunsiger, G. J. MacDougall, P. L. Russo, A. T. Savici, Y. J. Uemura, C. R. Wiebe, G. M. Luke, Phys. Rev. Lett. 2010, 105, 107203.

[110] C. Schlegel, E. Burzurí, F. Luis, F. Moro, M. Manoli, E. K. Brechin, M. Murrie, J. van Slageren, Chem. Eur. J. 2010, 16, 10178-10185.

[111] J. van Slageren, S. Dengler, J. Gomez-Segura, D. Ruiz-Molina, M. Dressel, Inorg. Chim. Acta 2008, 361, 3714-3717.

[112] L. Vergnani, A.-L. Barra, P. Neugebauer, M. J. Rodriguez-Douton, R. Sessoli, L. Sorace, W. Wernsdorfer, A. Cornia, Chem. Eur. J. 2012, 18, 3390 3398.

[113] F. Moro, D. Kaminski, F. Tuna, G. F. S. Whitehead, G. A. Timco, D. Collison, R. E. P. Winpenny, A. Ardavan, E. J. L. McInnes, Chem. Commun. 2014, 50, $91-93$

[114] K. R. Meihaus, J. D. Rinehart, J. R. Long, Inorg. Chem. 2011, 50, 8484 8489.

[115] N. Ishii, Y. Okamura, S. Chiba, T. Nogami, T. Ishida, J. Am. Chem. Soc. 2008, 130, 24-25. 
[116] C. Coulon, R. Clérac, W. Wernsdorfer, T. Colin, H. Miyasaka, Phys. Rev. Lett. 2009, 102, 167204.

[117] K. S. Gavrilenko, O. Cador, K. Bernot, P. Rosa, R. Sessoli, S. Golhen, V. V. Pavlishchuk, L. Ouahab, Chem. Eur. J. 2008, 14, 2034-2043.

[118] H. Miyasaka, K. Takayama, A. Saitoh, S. Furukawa, M. Yamashita, R. Clérac, Chem. Eur. J. 2010, 16, 3656-3662.

[119] I. Bhowmick, E. A. Hillard, P. Dechambenoit, C. Coulon, T. D. Harris, R. Clerac, Chem. Commun. 2012, 48, 9717-9719.

[120] F. Prins, E. Pasca, L. J. de Jongh, H. Kooijman, A. L. Spek, S. Tanase, Angew. Chem. Int. Ed. 2007, 46, 6081-6084; Angew. Chem. 2007, 119, 6193-6196.

[121] M. A. Palacios, S. Titos-Padilla, J. Ruiz, J. M. Herrera, S. J. A. Pope, E. K. Brechin, E. Colacio, Inorg. Chem. 2014, 53, 1465-1474.

[122] F. Pointillart, V. Kuropatov, A. Mitin, O. Maury, Y. Le Gal, S. Golhen, O. Cador, V. Cherkasov, L. Ouahab, Eur. J. Inorg. Chem. 2012, 4708-4718.

[123] W. Wernsdorfer, N. Aliaga-Alcalde, D. N. Hendrickson, G. Christou, Nature 2002, 416, 406-409.

[124] T. N. Nguyen, W. Wernsdorfer, M. Shiddiq, K. A. Abboud, S. Hill, G. Christou, Chem. Sci. 2016, 7, 1156-1173.

[125] A. Nava, L. Rigamonti, E. Zangrando, R. Sessoli, W. Wernsdorfer, A. Cornia, Angew. Chem. Int. Ed. 2015, 54, 8777-8782; Angew. Chem. 2015, 127, $8901-8906$.

[126] D. Pinkowicz, H. I. Southerland, C. Avendaño, A. Prosvirin, C. Sanders, W. Wernsdorfer, K. S. Pedersen, J. Dreiser, R. Clérac, J. Nehrkorn, G. G. Simeoni, A. Schnegg, K. Holldack, K. R. Dunbar, J. Am. Chem. Soc. 2015 $137,14406-14422$

[127] G. Poneti, K. Bernot, L. Bogani, A. Caneschi, R. Sessoli, W. Wernsdorfer, D. Gatteschi, Chem. Commun. 2007, 1807-1809.
[128] X. Yi, K. Bernot, O. Cador, J. Luzon, G. Calvez, C. Daiguebonne, O. Guillou, Dalton Trans. 2013, 42, 6728-6731.

[129] F. R. Fortea-Perez, M. Mon, J. Ferrando-Soria, M. Boronat, A. LeyvaPerez, A. Corma, J. M. Herrera, D. Osadchii, J. Gascon, D. Armentano, E. Pardo, Nat. Mater. 2017, 16, 760-766.

[130] M. Mon, J. Ferrando-Soria, M. Verdaguer, C. Train, C. Paillard, B. Dkhil, C. Versace, R. Bruno, D. Armentano, E. Pardo, J. Am. Chem. Soc. 2017 139, 8098-8101.

[131] J. Vallejo, F. R. Fortea-Perez, E. Pardo, S. Benmansour, I. Castro, J. Krzys tek, D. Armentano, J. Cano, Chem. Sci. 2016, 7, 2286-2293.

[132] Q. Chen, J. Li, Y.-S. Meng, H.-L. Sun, Y.-Q. Zhang, J.-L. Sun, S. Gao, Inorg. Chem. 2016, 55, 7980-7987.

[133] T. F. Mastropietro, N. Marino, G. D. Munno, F. Lloret, M. Julve, E. Pardo, D. Armentano, Inorg. Chem. 2016, 55, 11160-11169.

[134] M. Mon, A. Pascual-Álvarez, T. Grancha, J. Cano, J. Ferrando-Soria, F. Lloret, J. Gascon, J. Pasán, D. Armentano, E. Pardo, Chem. Eur. J. 2016 22, 539-545.

[135] D. Aulakh, H. Xie, Z. Shen, A. Harley, X. Zhang, A. A. Yakovenko, K. R. Dunbar, M. Wriedt, Inorg. Chem. 2017, 56, 6965-6972.

[136] Y. Li, T. Wang, H. Meng, C. Zhao, M. Nie, L. Jiang, C. Wang, Dalton Trans. 2016, 45, 19226-19229.

[137] J. J. Baldoví, E. Coronado, A. Gaita-Ariño, C. Gamer, M. Giménez-Marqués, G. Mínguez Espallargas, Chem. Eur. J. 2014, 20, $10695-10702$.

Manuscript received: January 9, 2018

Accepted manuscript online: February 13, 2018

Version of record online: March 24, 2018 